Tạp chi Khoa học và Công nghệ, Số 44, 2020

\title{
NGHIÊN CÚU QUY TRÌNH SẢN XUẤT BộT RONG NHO (Caulerpa lentilliera) HOÀ TAN
}

\author{
LÊ HƯONG THỦY \\ Viện Công nghệ Sinh học và Thực phẩm, Đại học Công nghiệp Thành phố Hồ Chí Minh \\ lehuongthuy@iuh.edu.vn
}

Tóm tắt. Bài báo này tập trung vào quy trình sản xuất bột rong nho hòa tan từ loài rong Caulerpa lentilliera sinh trưởng ở vùng biển Cam Ranh - Khánh Hòa. Công đoạn khử tanh bằng $\mathrm{NaHCO}_{3}$ ở các nồng độ $(0,3 \% \div 0,7 \%)$ trong thời gian từ 10 đến 30 phút theo tỷ lệ nguyên liệu/dung dịch $\mathrm{NaHCO}_{3}$ là $1 / 4$ $(\mathrm{v} / \mathrm{v})$, chiết dịch với sự hỗ trợ của pectinase ở các nồng độ $(0,3-0,7 \%)$ trong thời gian 20 đến 60 phút ở nhiệt độ $40^{\circ} \mathrm{C}$, và tối ưu hóa công đoạn sấy phun bằng phương pháp bề mặt đáp ứng Box-Behnken (maltodextrin $(5-15 \%)$, nhiệt độ sấy $\left(155-175^{\circ} \mathrm{C}\right)$, và tốc độ dòng nhập liệu $(20-30 \mathrm{ml} / \mathrm{ph})$ ) đã được nghiên cứu. Kết quả cho thấy, dung dịch $\mathrm{NaHCO}_{3} 0,5 \%$, tỉ lệ rong nho/dung dịch $\mathrm{NaHCO}_{3}$ là $1 / 4(\mathrm{v} / \mathrm{v})$ và thời gian 20 phút ngâm đã loại bỏ hoàn toàn mùi tanh của rong nho. Điều kiện chiết dịch có sự hỗ trợ của pectinase $0,5 \%$ trong 40 phút ở nhiệt độ $40^{\circ} \mathrm{C}$, và $\mathrm{pH}$ tự nhiên của rong nho là tốt nhất. Bột rong nho hòa tan có chất lượng tốt nhất thu được ở điều kiện tối ưu là nhiệt độ sấy phun $164^{\circ} \mathrm{C}$ với tỷ lệ maltodextrin là $11 \%$ và tốc độ dòng nhập liệu $23 \mathrm{ml} / \mathrm{ph}$.

Từ khóa. Caulerpa lentilliera, chiết, enzym pectinase, khử tanh, sấy phun.

\section{STUDY ON PRODUCTION PROCESS OF (Caulerpa lentillifera) INSTANT GRAPE SEAWEED POWDER}

Abstract: The paper focused on the production process of instant grape seaweed powder from Caulerpa lentilliera grown in the coast Cam Ranh - Khanh Hoa. Deodorant fishy step of grape seaweed using $\mathrm{NaHCO}_{3}$ at other concentration $(0.3 \% \div 0.7 \%)$ for 10 to 30 min with the ratio of material and $\mathrm{NaHCO}_{3}$ solution is $1 / 4(\mathrm{v} / \mathrm{v})$, the enzyme pectinase - assistant extraction in other enzyme concentration $(0.3-0.7 \%)$ for 20 to 60 minutes at $40^{\circ} \mathrm{C}$, and the drying spray optimization using the surface method of Box-Behnken (maltodextrin (5- 15\%), drying temperature $\left(155-175^{\circ} \mathrm{C}\right)$, and liquid feed speed $(20-30 \mathrm{ml} /$ minutes $\left.)\right)$, were studied. The results showed that the solution $\mathrm{NaHCO}_{3} 0.5 \%$, the grape seaweed-to-solution $\mathrm{NaHCO}_{3}$ ratio of $1 / 4(\mathrm{v} / \mathrm{v})$, and the soaking time of 20 minutes helped the full movement for deodorant fishy of grape seaweed. The $0.5 \%$ enzyme pectinase - assisted extraction condition for 40 minutes at $40^{\circ} \mathrm{C}$ and natural $\mathrm{pH}$ of grape seaweed was the best. The best instant grape seaweed powder was collected at the optimization condition, for example, spray drying temperature of $164^{\circ} \mathrm{C}$ with $11 \%$ maltodextrin and liquid feed speed of $23 \mathrm{ml} / \mathrm{min}$.

Keywords: Caulerpa lentilliera, extraction, enzym pectinase, deodorant fishy, spray drying.

\section{LỜI GIỚI THIỆU}

Rong nho, hay còn được gọi là trứng cá hồi xanh hay nho biển, là một loại rong biển có tên khoa học là Caulerpa lentillifera. Trên thế giới, rong nho mọc tự nhiên và được trồng nhiều ở Nhật Bản, Philippin và Thái Lan [1]. Ở Việt nam, rong nho được trồng nhiều ở các tỉnh duyên hải Nam Trung Bộ như Khánh Hoà, Bình Thuận, Phú Yên.

Rong nho là thực phẩm có giá trị dinh dưỡng cao và đã được sử dụng từ lâu ở Nhật Bản như một loại rau. Rong nho chứa nhiều axit amin thiết yếu như histidine, isoleucine, lysine, methionine, phenylalanine, threonine, tryptophan, valine, axit glutamic, axit aspartic. Ngoài ra, rong nho còn chứa nhiều vitamin, khoáng chất và nguyên tố vi lượng như vitamin $\mathrm{A}$, vitamin $\mathrm{C}$, canxi, magie, kali, natri, phospho, iot, sắt [1]. Trong thực tế, rong nho là một loại rong biển quý có giá trị dinh dưỡng cao, nhiều vitamin, chất khoáng, sinh tố đa lượng và vi lượng như: iot, canxi, vitamin $\mathrm{A}$, vitamin $\mathrm{B}$, vitamin $\mathrm{C}$, các acid amin ... nên rất hữa ích cho sức khỏe và hỗ trợ nhiều cho việc chữa bệnh cho người như: phòng bệnh ung thư, 
chữa trị bệnh tiểu đường, bệnh bướu cổ, rất tốt cho nhuận trường và giải độc gan, giảm cholesterol, ổn định huyết áp, tim mạch, tốt cho mắt, , xương khớp, ... Ngoài ra rong nho còn là sản phẩm làm đẹp da cho phụ nữ. Rong nho được dùng thường ngày chung với các loại thực phẩm khác.

Bột rong nho là một loại thực phẩm bổ dưỡng, dễ sử dụng và có khả năng tiêu thụ tốt ở thị trường nội địa cũng như có tiềm năng xuất khẩu cao. Hiện nay đã có một số quy trình sản xuất bột rong nho và nước uống rong nho do Trường Đại học Nha Trang nghiên cứu [2-7]. Các quy trình này đều bao gồm công đoạn chần rong nho bằng nước nóng và ngâm rong nho trong dung dịch sorbitol. Công đoạn chần giúp bất hoạt enzyme và giữ màu xanh cho rong nho. Công đoạn ngâm sorbitol giúp ổn định cấu trúc tế bào rong, tăng cường khả năng tái hydrat hoá của chúng sau sấy và ổn định hoạt tính chống oxy hoá của chúng [2, $3,8,9]$. Tiếp đó rong nho đem sấy khô sấy khô bằng thiết bị sấy bức xạ hồng ngoại kết hợp sấy lạnh, xay (nghiền) và rây để thu được bột rong nho thành phẩm $[2,4,5,6]$.

Tuy nhiên, việc xử lý rong nho bằng phương pháp chần, ngâm rửa khá phức tạp, mất nhiều thời gian và chi phí cho việc xử lý nguyên liệu. Sản phẩm rong nho thu được thường có mùi tanh. và quá trình xử lý nhiệt có thể làm tổn thất các vitamin tự nhiên và có thể ảnh hưởng đến sắc tố của rong nho. Do đó, cần có quy trình xử lý đơn giản giúp khử mùi tanh của bột rong nho thành phẩm hiệu quả. Bên cạnh đó sử dụng pectinase thủy phân thu dịch bảo tồn được giá trị dinh dưỡng của rong nho $[10,11]$, và công nghệ sấy phun [12], tạo sản phẩm bột rong nho hoà tan là giải pháp hữu ích nâng cao chất lượng sản phẩm. Bột rong nho hòa tan rất thuận tiện sử dụng để pha đồ uống giải khát và tăng lực, khoáng chất, vitamin, cho người dùng, đặc biệt trong điều kiện lao động, học tập với cường độ cao hoặc dùng cho vận động viên thể thao có khả năng tiêu th ụ tốt ở thị trường nội địa cũng như có tiềm năng xuất khẩu cao.

\section{NGUYÊN LIÊUU VÀ PHƯƠNG PHÁP}

\subsection{Nguyên liệu rong nho}

Rong nho (Caulerpa lentilliera) tươi sinh trưởng ở vùng biển Cam Ranh - Khánh Hòa, đã qua sơ chế xử lý (loại bỏ phần thân bò và phần bị hư hỏng) tại cơ sở sản xuất để thu rong đạt tiêu chuẩn chất lượng cơ sở, cụ thể: Chiều dài $<5 \mathrm{~cm}$ với số hạt cầu rong từ 98-120 hạt, đường kính trung bình rong nho 9,530 $\pm 0,302 \mathrm{~mm}$, đường kính trung bình của hạt cầu rong nho $2,120 \pm 0,133 \mathrm{~mm}$, và đường kính trung bình của thân rong nho $1,9100 \pm 0,0123 \mathrm{~mm}$. Rong nho được bọc trong các túi PE kín, có đệm lớp giấy thấm nước bên dưới và được vận chuyển vào thành phố Hồ Chí Minh để làm nguyên liệu nghiên cứu. Enzyme pectinase có hoạt độ $2600 \mathrm{UI} / \mathrm{ml}$ (Pectinex Ultra SP-L, Thụy Sĩ) được mua tại công ty TNHH Brenntag Việt $\mathrm{Nam}$, có nhiệt độ hoạt động tối ưu là $40^{\circ} \mathrm{C}$ ở $\mathrm{pH} 4,5$. Nồng độ thích hợp từ 0,3 đến $0,7 \%$, thời gian thủy phân từ 20 đến 60 phút, được bảo quản ở $5-10^{\circ} \mathrm{C}$. Công ty có địa chỉ ở số 202 , đường Hoàng Văn Thụ, phường 9, quận Phú Nhuận, thành phố Hồ Chí Minh.

\subsection{Phương pháp nghiên cứu}

\subsubsection{Thiết kế thí nghiệm}

Sơ đồ bố trí thí nghiệm tổng quát

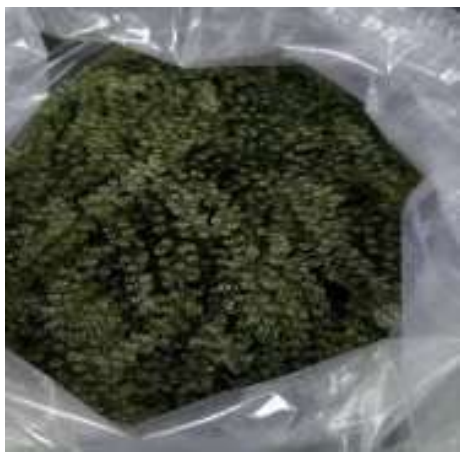

Hình 1: Nguyên liệu rong nho.

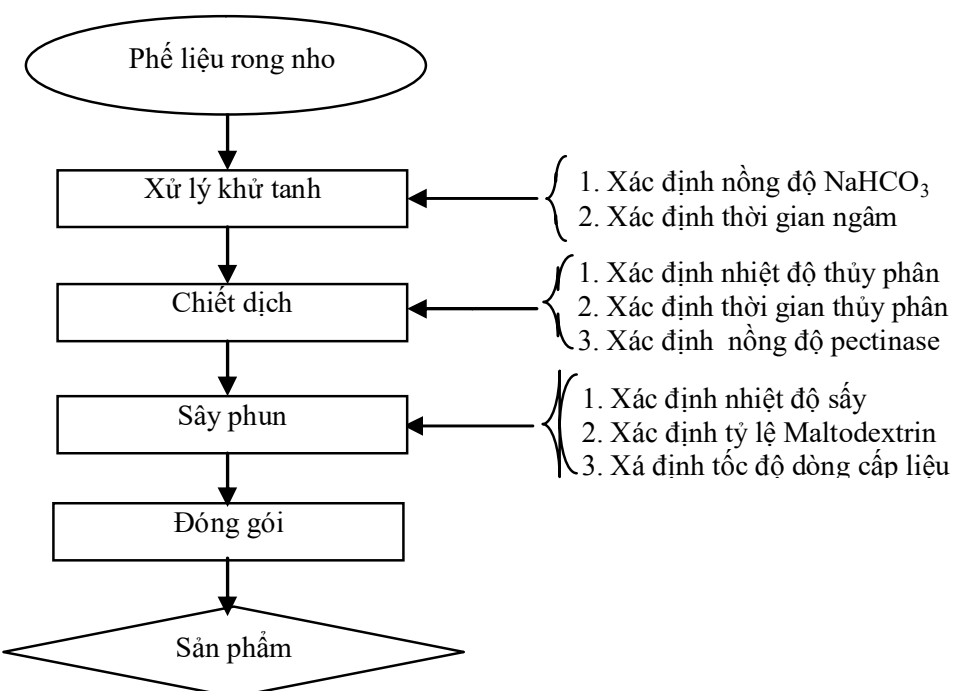

Hình 2: Sơ đồ tổng quát quy trình sản xuất bột rong nho hòa tan. 
Phương pháp xử lý mùi tanh: Tiến hành khảo sát $\mathrm{NaHCO}_{3}$ ở các nồng độ $(0,3 \% \div 0,7 \%)$ với bước nhảy $0,1 \%$ với mẫu đối chứng, trong thời gian từ $10-30$ phút với bước nhảy 5 phút, tỷ lệ nguyên liệu/dung dịch $\mathrm{NaHCO}_{3}=1 / 2$. Tiến hành đánh giá đo quang, tỷ lệ dịch chiết để lựa chọn nồng độ $\mathrm{NaHCO}_{3}$ và thời gian ngâm thích hợp.

Phương pháp thủy phân: Tiến hành nghiên cứu ảnh hưởng của các yếu tố đến quá trình thủy phân: bằng pectinase nồng độ $(0,3-0,7 \%)$ với bước nhảy $0,1 \%$, thời gian thủy phân $(20-60$ phút) với bước nhảy 20 phút, nhiệt độ thủy phân là $40^{\circ} \mathrm{C}$, Tiến hành đánh giá đo màu, đo độ nhớt, đo tỉ lệ dịch chiết và tỉ lệ bã thu được, hàm lượng gluxit có trong dịch chiết lựa chọn nồng độ pectinase và thời gian thủy phân rong nho thích hợp.

Tối ưu quá trình sấy phun: khảo sát điều kiện tối ưu hóa quá trình sấy phun bột rong nho bằng bằng phương pháp bề mặt đáp ứng, sử dụng mô hình thiết kế Box-Behnken cho 3 yếu tố của phần mềm Design Expert 7.0 với các thông số biên như sau: tỷ lệ bổ sung thêm chất trợ sấy maltodextrin (5-15\%) và nhiệt độ sấy phun ở $\left(155-175^{\circ} \mathrm{C}\right)$, tốc độ dòng nhập liệu $(20-30 \mathrm{ml} / \mathrm{ph})$. Hàm mục tiêu là trên hiệu suất thu hồi bột rong nho, và độ ẩm. Giá trị mã hóa của các yếu tố được trình bày trong bảng 1 . Bố trí thí nghiệm và kết quả tối ưu được trình bày ở bảng 4 .

Bảng 1: Bảng giá trị mã hóa của các yếu tố thực nghiệm.

\begin{tabular}{|l|c|c|c|c|}
\hline Biến độc lập & Ký hiệu & \multicolumn{3}{|c|}{ Mã hóa } \\
\cline { 3 - 5 } & & -1 & 0 & +1 \\
\hline Nhiệt độ đầu vào $\left({ }^{\circ} \mathrm{C}\right)$ & $\mathrm{A}$ & 5 & 10 & 15 \\
Tỷ lệ Maltodextrin $(\%)$ & $\mathrm{B}$ & 155 & 165 & 175 \\
Tốc độ dòng chảy $(\mathrm{ml} / \mathrm{ph})$ & $\mathrm{C}$ & 20 & 25 & 30 \\
\hline
\end{tabular}

\subsubsection{Các phương pháp phân tích}

- Đánh giá cảm quan dựa theo TCVN 3215-79 có sự hiệu chỉnh;

- Xác định độ ẩm và tổng hàm lượng chất khô theo TCVN 5102-1990;

- Xác định độ nhớt bằng nhớt kế S720, S750 (Canon, USA);

- Phân tích màu theo phương pháp đo màu sử dụng thiết bị Clorimeter;

- Hiệu suất thu hồi sản phẩm sấy phun dựa trên hiệu số khối lượng sản phẩm sau sấy phun so với khối lượng chất khô trong dịch nhập liệu.

\subsection{Phương pháp xử lý số liệu}

Thí nghiệm lặp lại 3 lần và thể hiện kết quả dưới dạng trung bình 3 lần lặp lại \pm độ lệch chuẩn. Mô phỏng dữ liệu bằng phần mềm MS. Excel 2010. Thiết kế thí nghiệm theo mô hình Box-Behnken, phân tích ANOVA, hồi quy, mối tương quan và tối ưu hóa bằng phần mềm Design Expert 7.0.

\section{KẾT QUẢ VÀ THẢO LUẬN}

\subsection{Thành phần dinh dưỡng của rong nho phế liệu}

Phân tích một số thành phần của rong nho phế liệu như hàm lượng béo, đạm, acid ascorbic, vitamin $\mathrm{A}$, độ ẩm, tro tổng, $\mathrm{Ca}, \mathrm{Mg}, \mathrm{Mn}, \mathrm{P}, \mathrm{K}, \mathrm{Na}, \mathrm{Zn}, \mathrm{Cu}, \mathrm{Fe}, \mathrm{Cd}, \mathrm{Pb}, \mathrm{As}, \mathrm{Hg}$, Iod đã có kết quả như sau:

Bảng 2: Thành phần hóa học của rong nho.

\begin{tabular}{|c|c|c|c|c|}
\hline $\mathrm{Stt}$ & Chỉ tiêu thử nghiệm & Đơn vị & Phương pháp thử & Kết quả \\
\hline 1 & Béo & $\%$ & $\begin{array}{l}\text { Phương pháp nội bộ (EHC - } \\
\text { TP2-050) }\end{array}$ & Không phát hiện $(\mathrm{LOD}=0,1)$ \\
\hline 2 & Đạm & $\%$ & $\begin{array}{l}\text { Phương pháp nội bộ (EHC - } \\
\text { TP2-047) }\end{array}$ & 0,51 \\
\hline 3 & Acid ascorbic & $\mathrm{mg} / 100 \mathrm{~g}$ & AOAC $2012.21 \mathrm{mod}$ & Không phát hiện $(\mathrm{LOD}=0,2)$ \\
\hline 4 & Retinol (Vitamin A) & $\mu \mathrm{g} / 100 \mathrm{~g}$ & AOAC $992.06 \bmod$ & Không phát hiện $(\mathrm{LOD}=10)$ \\
\hline 5 & Độ ẩm & $\%$ & $\begin{array}{l}\text { Phương pháp nội bộ (EHC - } \\
\text { TP2-048) }\end{array}$ & 95,4 \\
\hline 6 & Tro tổng & $\%$ & $\begin{array}{l}\text { Phương pháp nội bộ (EHC - } \\
\text { TP2-049) }\end{array}$ & 2,95 \\
\hline 7 & Canxi $(\mathrm{Ca})$ & $\mathrm{mg} / \mathrm{kg}$ & $\begin{array}{l}\text { Phương pháp nội bộ (EHC - } \\
\text { TP2-010) }\end{array}$ & 404 \\
\hline 8 & Magie $(\mathrm{Mg})$ & $\mathrm{mg} / \mathrm{kg}$ & $\begin{array}{l}\text { Phương pháp nội bộ (EHC - } \\
\text { TP2-010) }\end{array}$ & 1000 \\
\hline
\end{tabular}




\begin{tabular}{|c|c|c|c|c|}
\hline 9 & Mangan (Mn) & $\mathrm{mg} / \mathrm{kg}$ & AOAC $999.11 \mathrm{mod}$ & 4,20 \\
\hline 10 & Phospho (P) & $\%$ & AOAC 995.11 & $\begin{array}{l}\text { Không phát hiện } \\
\text { ( LOD }=0.02)\end{array}$ \\
\hline 11 & Kali (K) & $\mathrm{mg} / \mathrm{kg}$ & AOAC 969.23 & 504 \\
\hline 12 & Natri (Na) & $\mathrm{mg} / \mathrm{kg}$ & AOAC 969.23 & 11500 \\
\hline 13 & Kẽm (Zn) & $\mathrm{mg} / \mathrm{kg}$ & $\begin{array}{l}\text { Phương pháp nội bộ (EHC - } \\
\text { TP2-243) }\end{array}$ & $\begin{array}{c}\text { Phát hiện vết } \\
\qquad(<1,5)\end{array}$ \\
\hline 14 & Đồng $(\mathrm{Cu})$ & $\mathrm{mg} / \mathrm{kg}$ & $\begin{array}{l}\text { Phương pháp nội bộ (EHC - } \\
\text { TP2-243) }\end{array}$ & Không phát hiện $(\mathrm{LOD}=0,4)$ \\
\hline 15 & Sắt (Fe) & $\mathrm{mg} / \mathrm{kg}$ & $\begin{array}{l}\text { Phương pháp nội bộ (EHC - } \\
\text { TP2-243) }\end{array}$ & 9,7 \\
\hline 16 & Cadmium $(\mathrm{Cd})$ & $\mathrm{mg} / \mathrm{kg}$ & AOAC 2015.01 & 0,057 \\
\hline 17 & Chì $(\mathrm{Pb})$ & $\mathrm{mg} / \mathrm{kg}$ & AOAC 2015.01 & $\begin{array}{l}\text { Không phát hiện } \\
(\mathrm{LOD}=0,02)\end{array}$ \\
\hline 18 & Arsen (As) & $\mathrm{mg} / \mathrm{kg}$ & AOAC 2015.01 & 0,41 \\
\hline 19 & Thủy ngân (Hg) & $\mathrm{mg} / \mathrm{kg}$ & AOAC 2015.01 & $\begin{array}{l}\text { Không phát hiện } \\
(\mathrm{LOD}=0,004)\end{array}$ \\
\hline 20 & Hàm lượng Iốt & $\mu \mathrm{g} / \mathrm{kg}$ & AOAC 2012.15 & 4340 \\
\hline
\end{tabular}

(Kết quả phân tích tại Trung Tâm Eurofins- Sắc Ký Hải Đăng).

Đối chiếu với chỉ tiêu kim loại theo TCVN về nguyên liệu rong nho ta có bảng sau:

Bảng 3: Chỉ tiêu kim loại theo TCVN về nguyên liệu rong nho.

\begin{tabular}{|c|c|c|c|c|}
\hline STT & Chỉ tiêu phân tích & Đơn vị & Giới hạn cho phép & Kết quả \\
\hline 1 & Độ ẩm & $\%$ & $\leq 40$ & 95,4 \\
2 & Asen & $\mathrm{mg} / \mathrm{kg}$ & $\leq 1$ & 0,41 \\
3 & $\mathrm{~Pb}$ & $\mathrm{mg} / \mathrm{kg}$ & $\leq 2$ & Không phát hiện \\
4 & $\mathrm{Cd}$ & $\mathrm{mg} / \mathrm{kg}$ & $\leq 0,05$ & 0,057 \\
5 & $\mathrm{Hg}$ & $\mathrm{mg} / \mathrm{kg}$ & $\leq 0,05$ & Không phát hiện \\
\hline
\end{tabular}

(Kết quả phân tích tại Trung Tâm Eurofins- Sắc Ký Hải Đăng).

Các thành phần như chất béo, vitamin $\mathrm{A}$, Vitamin $\mathrm{C}, \mathrm{P}, \mathrm{Zn}, \mathrm{Cu}, \mathrm{Pb}$, và $\mathrm{Hg}$ không được phát hiện trong mẫu đã phân tích. Hàm lượng đạm trong rong nho $(0,51 \%, \mathrm{DW})$ là thấp so với các loài rong nâu và rong lục khác (Bảng 2). Các nguyên tố vi lượng và chất khoáng thiết yếu cho cơ thể như Canxi, Magie, Photpho, Natri, Kali, Đồng, Kẽm.. chiếm tỉ lệ khá lớn so với chất khô. Quá trình chuyển hóa chất trong cơ thể không thể thiếu những khoáng chất quan trọng này. Iốt là vi chất quan trọng để tuyến giáp tổng hợp các hormon điều chỉnh quá trình phát triển của hệ thần kinh trung ương, phát triển hệ sinh dục và các bộ phận trong cơ thể như tim mạch, tiêu hóa, da - lông - tóc - móng, duy trì năng lượng cho cơ thể hoạt động. Thành phần các ion kim loại trong rong nho nguyên liệu là đạt chuẩn so với tiêu chuẩn QCVN 82:2011/BYT của Bộ $\mathrm{Y}$ tế và điều này cho thấy nguyên liệu rong nho sử dụng trong nghiên cứu này đảm bảo vệ sinh dùng cho thực phẩm (Bảng 2 và 3 ).

3.2. Khử tanh phế liệu rong nho bằng $\mathrm{NaHCO}_{3}$

Tiến hành khử tanh nguyên liệu rong nho bằng cách ngâm rong nho trong dung dịch $\mathrm{NaHCO}_{3}$, khảo sát nồng độ dung dịch $\mathrm{NaHCO}_{3}$ từ $0,3 \%$ đến $0,7 \%$ bước nhảy $0,1 \%$ với mẫu đối chứng, trong thời gian từ 10 30 phút bước nhảy 5 phút, tỷ lệ nguyên liệu rong nho/dung dịch $\mathrm{NaHCO}_{3}=1 / 2$. Kết quả đánh giá cảm quan các mẫu cho thấy nguyên liệu rong nho xử lý ở nồng độ $\mathrm{NaHCO}_{3} 0,5 \%$ và thời gian ngâm trong dung dịch 20 phút có điểm đánh giá cảm quan là cao nhất so với các mẫu khác, nguyên liệu rong nho đạt trạng thái giòn, cứng, không nhũn, không nhớt, màu sắc không bị thay đổi, đồng thời mùi tanh của rong nho giảm đáng kể (Hình 3 và 4 ). Do đó chế độ xử lý khử mùi tanh của nguyên liệu rong nho lựa chọn là nồng độ muối $\mathrm{NaHCO}_{3}$ là $0,5 \%$ và thời gian ngâm khử mùi tanh trong 20 phút. 


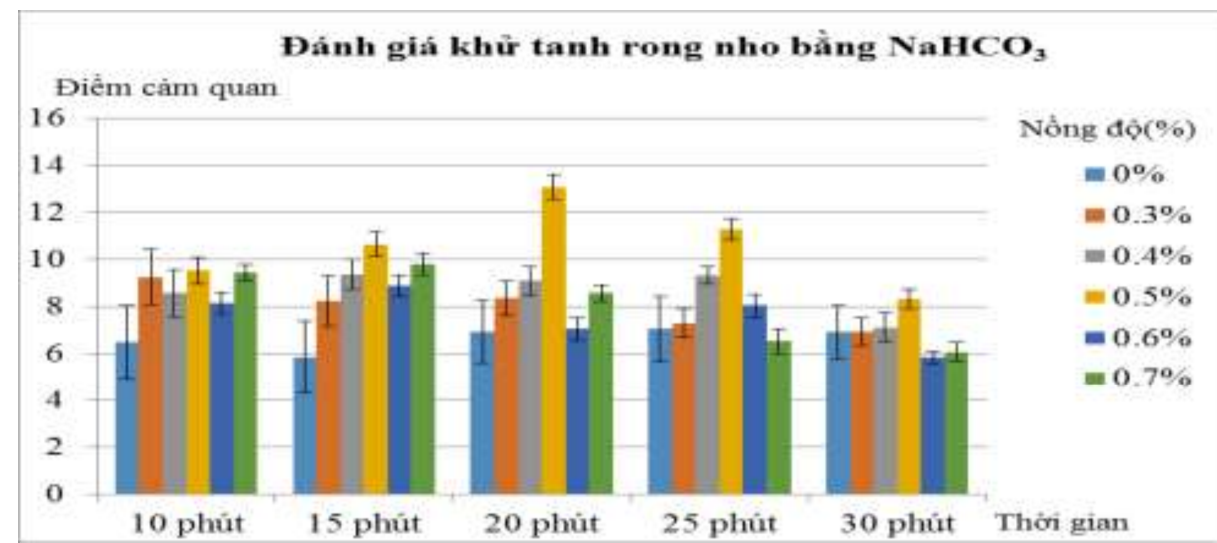

Hình 3: Ảnh hưởng của nồng độ $\mathrm{NaHCO}_{3}$ và thời gian ngâm khử mùi tanh của nguyên liệu rong nho.

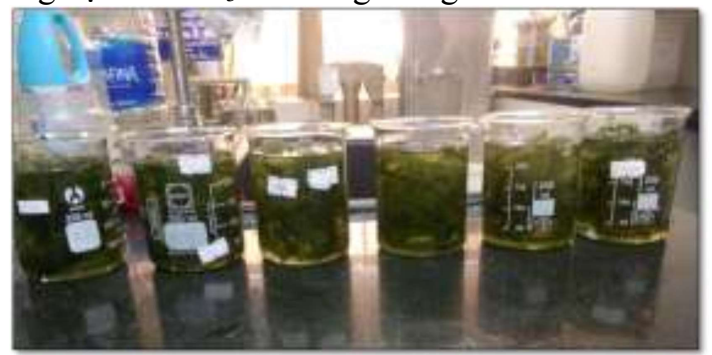

Hình 4: Ngâm rong nho trong dung dịch $\mathrm{NaHCO}_{3}$ ở các nồng độ khác nhau.

\subsection{Kết quả chiết dịch nguyên liệu rong nho bằng pectinase}

Kết quả cho thấy, nhiệt độ thủy phân cao làm ức chế hoạt động của Enzyme, phá hủy sắc tố Clorophyl trong phế liệu rong nho chuyển sang màu đen, màu sắc của dịch chiết rong nho sau khi thủy phân với nhiệt độ cao cũng bị đổi màu, không giữ được màu xanh lá mạ như ban đầu. Do đó ta thấy ở nhiệt độ 40$45^{\circ} \mathrm{C}$ thích hợp cho hoạt động của pectinase, lượng dịch thu được nhiều hơn, bên cạnh đó màu sắc của dịch chiết rong nho ít bị biển đồi. Đối với yếu tố $\mathrm{pH}$ thì $\mathrm{pH}$ của rong nho từ $4,5-5,0$ là $\mathrm{pH}$ tối thích hoạt động của pectinase vì vậy chọn $\mathrm{pH}$ tự nhiên để thủy phân rong nho.

Lấy 5 becher mỗi becher chứa $100 \mathrm{ml}$ rong nho đã xay nhỏ. Bổ sung pectinase ở các tỷ lệ $0 \%, 0,3 \%$, $0,4 \%, 0,5 \%, 0,6 \%, 0,7 \%$ vào từng mẫu so với $100 \mathrm{ml}$ dịch rong nho. Sau đó đem ủ ấm ở nhiệt độ $40^{\circ} \mathrm{C}$ trong 20 phút, 40 phút và 60 phút, kết quả như sau:

Hình 5: Ảnh hưởng của nồng độ pectinase và thời gian tới sự thủy phân dịch.

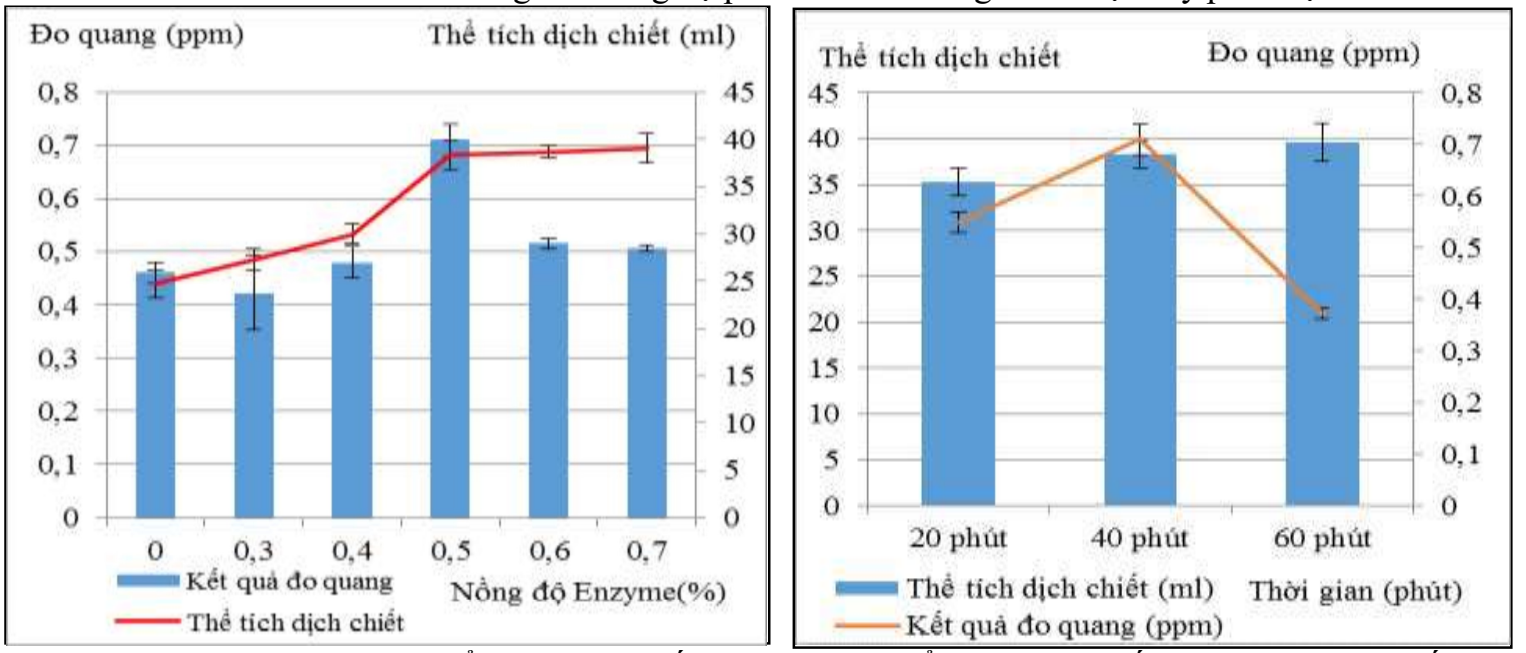

Pectinase ảnh hưởng lên thể tích dịch chiết thu được và thể tích dịch chiết thu được có sự biến thiên theo nồng độ (Hình 5). Đối với đo quang về màu sắc của dịch thấy rằng, ở nồng độ $0.5 \%$ cho mức đo quang cao nhất so với các nồng độ còn lại. Đồng thời thông qua giá trị $\mathrm{P}_{\text {value }}<0,05$ nên có sự khác biệt 
giữa các nồng độ. Vì vậy sẽ chọn nồng độ $0,5 \%$ thì lượng dịch chiết vừa nhiều, vừa có màu sắc đẹp và tiết kiệm được chi phí, hóa chất... và hiệu xuất thu hồi cao nhất. Kết quả này tương đương với thông báo của Nguyễn Nhật Minh Phương về tác động enzyme đến khả năng trích ly dịch quả [10].

Khảo sát ảnh hưởng của thời gian thủy phân ta thấy thời gian càng dài thì lượng dịch càng tăng, tuy nhiên kết quả đo quang cho thấy ở thời gian 40 phút thì kết qủa đo quang là cao nhất, vì mục tiêu thủy phân rong nho bằng pectinase tạo được dịch chiết nhiều cũng như mầu sắc đẹp nhất (xanh lá mạ), giữ được màu sắc tự nhiên của rong nho do đó chọn thời gian 40 phút để phù hợp với mục tiêu đề ra.

\subsection{Tối ưu hóa quá trình sấy phun}

Trên cơ sở thí nghiệm thăm dò để chọn vùng ảnh hưởng của các yếu tố (nhiệt độ, tỷ lệ phối trộn chất trợ sấy Maltodextrin, tốc độ dòng nhập liệu) đển quá trình sấy phun tạo bột rong nho hòa tan, tiến hành tối ưu hóa bằng phương pháp bề mặt đáp ứng, sử dụng mô hình thiết kế Box-Behnken của phần mềm Design Expert 7.0 quá trình sấy phun với các thông số biên như sau: nhiệt độ sấy phun ở $\left(155-175^{\circ} \mathrm{C}\right)$, tỷ lệ bổ sung thêm chất trợ sấy maltodextrin (5- 15\%) và tốc độ dòng nhập liệu $(20-30 \mathrm{ml} / \mathrm{ph})$ (Bảng 4). Kết quả 17 thí nghiệm thực nghiệm tối ưu theo mô hình thiết kế Box-Behnken như sau.

Bảng 4: Bảng thiết kế và kết quả thực nghiệm.

\begin{tabular}{|c|c|c|c|c|c|}
\hline STT & $\begin{array}{c}\text { Nhiệt độ sấy } \\
\left({ }^{\circ} \mathrm{C}\right)\end{array}$ & $\begin{array}{c}\text { Tỷ lệ maltodextrin } \\
(\%)\end{array}$ & $\begin{array}{c}\text { Tốc độ dòng } \\
(\mathrm{ml} / \mathrm{ph})\end{array}$ & $\begin{array}{c}\text { Độ ẩm } \\
(\%)\end{array}$ & $\begin{array}{c}\text { Tỷ lệ thu hồi } \\
(\%)\end{array}$ \\
\hline 1 & - & - & 0 & 7,83 & 7,28 \\
2 & + & - & 0 & 5,26 & 9,88 \\
3 & - & + & 0 & 8,31 & 11,67 \\
4 & + & + & 0 & 5,20 & 12,67 \\
5 & - & 0 & - & 6,42 & 10,3 \\
6 & + & 0 & - & 5,56 & 12,78 \\
7 & - & 0 & + & 8,64 & 11,89 \\
8 & + & 0 & + & 5,98 & 12,38 \\
9 & 0 & - & - & 5,38 & 11,49 \\
10 & 0 & + & - & 5,86 & 9,08 \\
11 & 0 & - & + & 5,06 & 8,74 \\
12 & 0 & + & + & 5,86 & 12,56 \\
13 & 0 & 0 & 0 & 6,92 & 12,96 \\
14 & 0 & 0 & 0 & 7,02 & 13,02 \\
15 & 0 & 0 & 0 & 7,26 & 13,14 \\
16 & 0 & 0 & 0 & 6,76 & 13,78 \\
17 & 0 & 0 & 0 & 6,98 & 12,86 \\
\hline
\end{tabular}

Kết quả cho thấy, nhiệt độ sấy phun, tỷ lệ chất trợ sấy maltodextrin và tốc độ dòng nhập liệu đều ảnh hưởng đến độ ẩm và tỷ lệ thu hồi bột rong $(\mathrm{p}<0.05)$ (Bảng 5).

Bảng 5 : Phương trình hồi quy của độ ẩm và tỷ lệ thu hồi bột rong.

\begin{tabular}{|c|c|c|c|c|}
\hline Hằng số/ & \multicolumn{2}{|c|}{ Độ ẩm $\mathrm{Y}_{1}$} & \multicolumn{2}{c|}{ Tỷ lệ thu hồi $\mathrm{Y}_{2}$} \\
\cline { 2 - 5 } Biến số & Hệ số & $\mathrm{p}_{\text {value }}$ & Hệ số & $\mathrm{p}_{\text {value }}$ \\
\hline Hằng số & 6,99 & 0,0082 & 13,152 & 0,0058 \\
$\mathrm{~A}$ & $-1,15$ & 0,0004 & 0,82125 & 0,0260 \\
$\mathrm{~B}$ & 0,21 & 0,2868 & 1,07375 & 0,0079 \\
$\mathrm{C}$ & 0,29 & 0,1596 & 0,24 & 0,4381 \\
$\mathrm{AB}$ & $-0,14$ & 0,6205 & $-0,4$ & 0,3649 \\
$\mathrm{AC}$ & $-0, .45$ & 0,1279 & $-0,4975$ & 0,2673 \\
$\mathrm{BC}$ & 0,080 & 0,7678 & 1,5575 & 0,0070 \\
$\mathrm{~A} 2$ & 0,39 & 0,1725 & $-0,7035$ & 0,1239 \\
$\mathrm{~B} 2$ & $-0,72$ & 0,0247 & $-2,0735$ & 0,0013 \\
$\mathrm{C} 2$ & $-0,72$ & 0,0247 & $-0,611$ & 0,1727 \\
Phương trình & $\mathrm{Y}_{1}=6,99-1,15 * \mathrm{~A}-0,72 * \mathrm{~B}^{2}-0,72 *$ & $\mathrm{Y} 2=13,15+0,82 * \mathrm{~A}+1,07 * \mathrm{~B}+1,56 *$ \\
hồi quy & $\mathrm{C}^{2}$ & & \multicolumn{2}{c}{$\mathrm{B} * \mathrm{C}-2,07 * \mathrm{~B}^{2}$} \\
\hline
\end{tabular}

Kết quả cho thấy, các giá trị hệ số tự do của phương trình hồi quy có ý nghĩa thống kê $\left(\mathrm{P}_{1-\text { value }}=\right.$ 0,0082 và $\mathrm{P}_{2}-$ value $=0,0058$ ) (Bảng 5 ). Hệ số tương quan của mô hình đáp ứng $\mathrm{Y}_{1}$ và $\mathrm{Y}_{2}$ đều có tương 
ứng là $\mathrm{R}^{2} 0,90$ và 0,91 chứng tỏ mô hình thực nghiệm có độ tin cậy cao và phù hợp. Phân tích ANOVA kết quả 17 thí nghiệm thực nghiệm tối ưu thu được phương trình hồi quy và bề mặt đáp ứng (3D) của độ ẩm và tỷ lệ thu hồi bột rong nho theo nhiệt độ sấy phun, tỷ lệ bổ sung thêm chất trợ sấy maltodextrin và, tốc độ dòng nhập liệu (Hình 6) như sau:
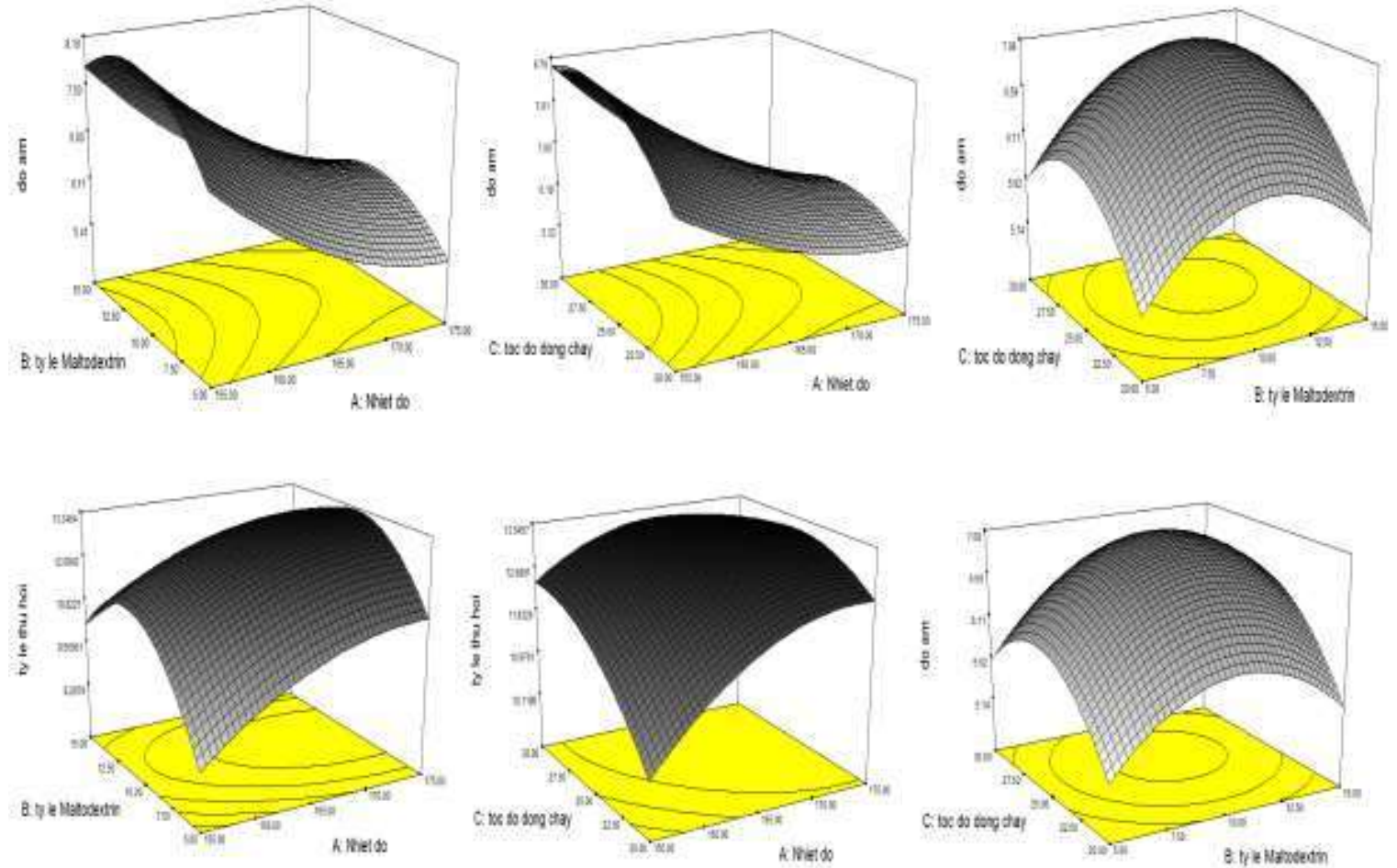

Hình 6: Đường đồng mức và bề mặt đáp ứng (3D) của độ ẩm và tỷ lệ thu hồi bột rong nho theo nhiệt độ sấy phun, tỷ lệ bổ sung thêm chất trợ sấy maltodextrin và tốc độ dòng nhập liệu.

Mô hình đáp ứng cho thấy điều kiện tối ưu của quá trình sấy phun bột rong nho là: nhiệt độ sấy phun $164{ }^{\circ} \mathrm{C}$, tỷ lệ bô sung thêm chất trợ sấy maltodextrin $11 \%$ và, tốc độ dòng nhập liệu $23 \mathrm{ml} / \mathrm{ph}$. Trên cơ sở các điểm tiên đoán từ mô hình, tiến hành thí nghiệm để kiểm chứng cho thấy sự tương thích giữa lý thuyết và thực nghiệm. Kết quả thí nghiệm kiểm tra thể hiện khoảng dự đoán của mô hình và độ lệch so với giá trị mô hình dự doán của mô hình nhỏ (Bảng 6). Điều kiện sấy phun tạo bột rong nho là $164^{\circ} \mathrm{C}$, tỷ lệ maltodextrin $11 \%$ và tốc độ dòng nhập liệu $23 \mathrm{ml} / \mathrm{ph}$. Kết quả này tương tự với công bố của Tôn Nữ Minh Nguyệt trên bột chanh dây (nhiệt độ không khí đầu $165^{\circ} \mathrm{C}$ và tốc độ bơm nhập liệu là $22,5 \mathrm{ml} / \mathrm{ph}$ ) [12].

Bảng 6. Kết quả thí nghiệm kiểm tra điều kiện mô hình dự đoán.

\begin{tabular}{|c|c|c|c|c|c|c|}
\hline Nhiệt độ & $\begin{array}{c}\text { Tỷ lệ } \\
\text { maltodextrin }\end{array}$ & $\begin{array}{c}\text { Tốc độ } \\
\text { dòng }\end{array}$ & Hàm mục tiêu & Tiên đoán & $\begin{array}{c}\text { Khoảng dự } \\
\text { đoán }\end{array}$ & $\begin{array}{c}\text { Thực } \\
\text { nghiệm }\end{array}$ \\
\hline 164 & 11 & 23 & Độ ẩm (\%) & 6,82 & $6,28 \div 7,36$ & $6,87 \pm 0,08$ \\
$\left({ }^{\circ} \mathrm{C}\right)$ & $(\%)$ & $(\mathrm{ml} / \mathrm{ph})$ & Tỷ lệ thu hồi $(\%)$ & 12,95 & $12,09 \div 13.8$ & $13,02 \pm 0,06$ \\
\hline
\end{tabular}

\section{KẾT LUẬn}

Kết quả cho thấy, mùi tanh rong nho đạt tiêu chuẩn QCVN 8-2:2011/BYT của Bộ Y tế được khử bằng dung dịch $\mathrm{NaHCO}_{3} 0,5 \%$ theo tỉ lệ nguyên liệu rong nho/dung dịch là $1 / 4(\mathrm{v} / \mathrm{v})$ trong thời gian 20 phút. Dịch thủy phân rong nho chuẩn bị cho sấy phun được thu nhận bằng cách ngâm rong trong pectinase nồng độ $0,5 \%$ với thời gian 40 phút ở nhiệt độ $40^{\circ} \mathrm{C}$ trong điều kiện $\mathrm{pH}$ tự nhiên của rong nho. Bột rong nho được thu nhận bằng cách sấy phun dịch chiết ở điều kiện nhiệt độ $164^{\circ} \mathrm{C}$ với chất trợ sấy maltodextrin $11 \%$ và tốc độ nhập liệu $23 \mathrm{ml} / \mathrm{ph}$ có khả năng hòa tan $100 \%$ và đạt chất lượng tốt nhất so với các điều kiện sấy phun khác đã được khảo sát trong nghiên cứu này. Nghiên cứu này mới chỉ nghiên cứu chuẩn bị dịch chiết rong nho với sự hỗ trợ của pectinase mà chưa tìm thấy enzyme khác. Kết quả cho thấy, quy 
trình sản xuất bột rong nho phù hợp với điều kiện ở Việt Nam và sản phẩm bột rong nho hoàn toàn có thể ứng dụng trong thực phẩm và mỹ phẩm.

\section{TÀI LIẸU THAM KHẢO}

[1]. Nisizawa K., H. Noda, R. Kikuchi, and T. Watanabe, The main seaweed food in Japan, Hydrobilologia, vol 151, no. 152 , pp. 5-29, 1987.

[2]. Vũ Ngọc Bội, Nguyễn Thị Mỹ Trang, và Trần Thị Hồng Nhung, Ảnh hưởng của một số yếu tố công nghệ lên chất lượng bột rong nho, Tạp chỉ Khoa học - Công nghệ Thuỷ sản, số 2, trang 20 - 26, 2015.

[3]. Huỳnh Hữu Hoài, Nghiên cứu sử dụng Vicozyme trong sản xuất nước uống từ rong nho (Caulerpa lentillifera), Đồ án tốt nghiệp đại học Trường Đại học Nha Trang, 2013.

[4]. Võ Thị Hướng, Nghiên cứu sản xuất bột rong nho khô, Đồ án tốt nghiệp đại học Trường Đại học Nha Trang, 2013.

[5]. Nguyễn Thị Nhung, Nghiên cứu sấy khô rong nho và sơ bộ thử nghiệm rong nho tuơi vào nước giải khát, Đồ án tốt nghiệp đại học. Trường Đại học Nha Trang, 2012.

[6]. Phạm Thị Thanh Tuyền, Nghiên cưu hoàn thiện quy trình chế biến bột rong nho khô, Đồ án tốt nghiệp đại học. Trường Đại học Nha Trang, 2014.

[7]. Nguyễn Trần Anh Vũ, Nghiên cưu chế biến nước rong biển đóng chai, Đồ án tốt nghiệp đại học. Trường Đại học Nha Trang, 2010.

[8]. Lê Thị Hồng, Nghiên cúu ảnh huơơng của nhiệt độ bảo quản đến chất lượng và thời gian bảo quản của rong nho (Caulerpa lentillifera) tuooi, Đồ án tốt nghiệp đại học. Trường Đại học Nha Trang, 2015.

[9]. Trần Huỳnh Tâm Lĩnh, Nghiên cưu sản xuất rong nho khô nguyên thể, Đồ án tốt nghiệp đại học. Trường Đại học Nha Trang, 2013.

[10]. Nguyễn Nhật Minh Phương, Lý Nguyễn Bình, Châu Trần Diễm Ái, và Chế Văn Hoàng, Tác động enzyme Pectinase đến khả năng trích ly dịch quả và các điều kiện lên men đến chất lượng rượu vang Xoài sau thời gian lên men chính, Số 20a, trang 127-136, 2011.

[11]. Nguyễn Văn Quý, Nghiên cứu ưng dụng enzyme pectinase trong chiết tách dịch quả nhàu và thử nghiệm sản xuất nước giải khát tù̀ quả nhàu, Luận văn tốt nghiệp Thạc sĩ. Đại học Đà Nẵng, 2011.

[12]. Tôn Nữ Minh Nguyệt, và Đào Văn Hiệp, Nghiên cứu ứng dụng kỹ thuật sấy phun trong sản xuất bột chanh dây, Tạp chi Phát triển Khoa học và Công nghệ, tập 9, số 4, trang 69 - 75, 2006. 